\title{
HERD BEHAVIOR IN TERMS OF SOCIAL PSYCHOLOGY: THE EXAMPLE OF CRYPTO ASSET MARKETS
}

\section{-RESEARCH ARTICLE-}

\author{
Nükhet HOTAR \\ Prof. Dr., Dokuz Eylül University, Faculty of Economics and Administrative Sciences, \\ Labour Economics and Industrial Relations, Turkey \\ EMAIL : nukhethotar@deu.edu.tr \\ ORCID ID : 0000-0002-2195-0852
}

\begin{abstract}
-Abstract-
The four main causes of sudden price fluctuations in crypto asset markets are speculative news within the scope of global developments, positive market perceptions that increase the price, rising stock market values, and herd behavioral tendencies on crypto assets. The purpose of this study is to examine herd behavior trends in terms of social psychology, exemplified by the crypto asset market. In this framework, firstly, the daily yield pricing of twenty-two crypto assets with the highest transaction volume was examined in the period of August 2013 December 2019, and then the trend of herd behavior of these assets on the market was investigated. Cross Sectional Absolute Deviation (CSAD) method was used to measure the herd behavior trend. The analysis revealed the presence of herd behavior trend in regime 1 and regime 3 models.
\end{abstract}

Keywords: Social Psychology, Herd Behavior, Crypto Asset, Cross Sectional Absolute Deviation (CSAD), Cryptocurrency.

JEL Classification: G1, G2

\section{INTRODUCTION}

Crypto coins are gaining popularity against classical currencies due to their dynamic structure. The interest of investors and researchers in the crypto asset market has moved from a focus on a single virtual currency towards researching the structure and features of the asset market. The production of these assets has a completely user-based model, it draws attention because it is controlled by no government or central authority (Ağan and Aydın, 2019: 2). However, the increasing demand for these assets and the limited amount that can be produced has led to the emergence of sub-currencies for each virtual currency. Rapidly growing since 2013, Bitcoin also encourages the creation of other coins with different functions. In addition, the design and usage of cryptocurrencies provides an alternative for users in facilitating the process of ownership, transactions and money creation.

Unlike traditional currencies, cryptocurrencies do not require trusted third parties to address authorization or other security issues. The decentralized structure of cryptocurrencies allows security issues to be addressed through special algorithms. Security against external threats and

Citation(APA): Hotar, N., (2020), Herd Behavior in Terms of Social Psychology: The Example Of Crypto Asset Markets, International Journal of eBusiness and eGovernment Studies, 12 (1): 79-90. Doi:10.34111/ijebeg.202012106 
attacks is provided by a technology called "blockchain". Since the first appearance of crypto assets in 2009 with the broad-market volume of Bitcoin, more than 2000 cryptocurrencies have been released and are now open to trading in international markets.

It is becoming increasingly difficult for economists to understand the recent collapse in stock markets. The financial economy's theoretical foundationsare based on the assumption of the effectiveness of markets (Fama, 1970). In addition, the assumption that individuals act in a way that maximizes their interests is the basis for strong theories for investors in the field of finance. However, researchers have found empirical evidence which contradicts the assumptions of traditional finance theories. While this process contributes to the development of behavioral finance, researchers are now aware that investors may act irrationally (Aydın \& Ağan, 2016: 98). Therefore, investor psychology and the effect of psychological factors in the decisionmaking process can cause many anomalies in the markets, and affect the functioning of the market structure. Behavioral finance reveals that investors engage in systematic deviations from rationality. According to behavioral finance, individuals decide under the influence of their cognitive bias and herd behavior, which leads to financial market ineffectiveness, fragility, and the presence of anomalies. Crypto asset markets are observed to be largely in line with the ideas posed by behavioral finance advocates for financial markets.

Behavioral finance studies aim to explain the behavior of professional and non-professional investors with theories derived from social sciences, such as psychology, sociology, social psychology and anthropology. This study focuses on the herd behavior in terms of social psychology. Herd behaviour in financial markets often arises from trends in investors' cognitive and psychological prejudices. This tendency has been observed and researched in financial institutions, especially during the global financial crisis. The purpose of this study is to measure investors' tendency towards herd behavior through price movements in the crypto asset market. Another goal to examine the crypto asset market under the following hypothesis: cryptoinvestors have limited resources and abilities to process the weak prior knowledge and information. This study contributes to the literature by providing social psychology perspectives on the expanding crypto money market. In this context, firstly, a literature review was conducted, and then method and analysis results were evaluated.

\section{LITERATURE REVIEW}

There is no consensus on how to value crypto assets stored with an encryption technology. Some researchers find Bitcoin and other encryption transactions fraudulent, while others see it as the technology of the future, and because of this disagreement, financial analysts rarely recommend cryptocurrencies. Cryptocurrency markets are highly dependent on socially produced ideas and events, as many who participate the cryptocurrency markets are young, inexperienced investors who are easily influenced by social media, chat rooms and various online forums. Crypto assets can lead to unfair price levels, unless a balance between earnings and loss can be achieved. Cryptocurrency traders are unlike stock traders in that they are not sensitive to negative shocks, which do not automatically lead to high sales in the cryptocurrency market. Herd behavior requires the coordination of the ability to observe the actions of others or a price movement (Devenow \& Welch, 1996). Such mechanisms are found in crypto asset markets; it continues to develop in the internet era, where networks and social media facititate the sharing of ideas and information. In fact, the business transactions of large cryptocurrency holders called "whales" can be easily observed via "crypto currency whale watching" through websites that allow the tracking of whales and their transactions. Another factor is that Bitcoin and other crypto assets are not considered securities. 
In their studies, Şanlısoy and Çiloğlu examined the emergence of cryptocurrencies and how the savings income of central banks would be affected by this process and evaluated the future of the global reserve money system (Şanlısoy and Çiloğlu, 2019).

In the context of behavioral finance, herd behavior is defined as a decision-making approach characterized by imitating the actions of others, or "a situation where rational people start to act rationally by imitating others' judgments while making decisions". In other words, it is defined as any behavior similarity / difference transmitted by the interaction of individuals (Hirshleifer and Hong Teoh 2003).

In their studies, Bevan-Dye (2018) examined the social media behavior of university students in generation Y. The importance of electronic word-of-mouth communication (eWom) is emphasized. In this study, 311 student's data were used in 4 different campuses in South African universities. The data of these students such as information link sharing and product link sharing on Facebook were examined. Thus, the results of students' affecting each other were examined. Structural equation modeling, correlation analysis, constructvalidity analysis and reliability analysis were used as data analysis method.

According to Graham (1999), herd behavior can be organized in four different categories: informational herd, reputable herd, researcher herd, and experimental herd. In informational herd behavior, individuals choose to ignore their private information (optimally) and imitate the actions of individuals (Banerjee 1992; Bikhchandani, Hirshleifer and Welch 1992). In the context of Bayesian reasoning, it refers to the process of updating information by gradually reducing the previous weight, as new and supposedly more powerful information is presented in a sequential order. In other words, it assumes that the likelihood ratios, which are characterized as private signals, are limitless. As a result, individuals in the chain of later events; due to the overwhelming nature of their beliefs, prejudices, and psychological tendencies, the chain of events may be imitated, and consequently this will not provide useful information for individuals.

Herd behavior among investors has been described as volatility changefulness, and addressed in empirical studies, which reveal that a short-term popular behavior can be observed in financial markets (Lakonishok et al. 1992; Christie \& Huang, 1995; Chang et al., 2000; Hwang \& Salmon, 2004; Demirer et al., 2010).

In recent years, many researchers have focused their various analyses on Bitcoin due to its unique features and outstanding performance (Cheah \& Fry, 2015; Urquhart, 2017; Katsiampa, 2017). The interest of investors and researchers on Bitcoin is related to approaches that try to understand, explain and analyze the key features of the crypto asset market, rather than just focusing on a digital currency. Corbet et al. (2018) examines the presence of balloons in Bitcoin and Ethereum, underlining that key findings (mixed chain, block chain and liquidity) do not cause any balloons in the market. Wei (2018), examining the efficiency of cryptocurrencies, highlights the positive relationship between the efficiency of cryptocurrencies and transaction volume. Platanakis et al. (2018) claims that diversification through Bitcoin, Litecoin, Ripple and Dash is as equally effective as optimal diversification.

Attempts by economists and investors to understand herd behavior have attracted great attention in recent years. Christie and Huang (1995); Chang et al. (2000); Gleason et al. (2004) investigating the US stock exchange, rejected the hypothesis of the absence of herd behaviour. However, Chiang and Zheng (2010) provided evidence of herd behavior in developed European countries. Chiang and Zheng (2010)'s position, however, conflicts with the earlier literature showing no herding in either the Chinese (Demirer et. al, 2010) or advanced markets (Chang et al., 2000). 
Crypto assets appear to exhibit excessive returns and volatility from time to time without relying on a report. Irrational investors who rely on unproven information operate on this market without fully analyzing the risks. Therefore, investors are observed to follow the behavior of others regardless of their own analysis. This can cause potential herd behavior. Bouri et al. (2018), taking into account structural breaks and nonlinearity, Chang et al. (2000) showed that there is a herd behavior in the cryptocurrency market by using the Cross Sectional Absolute Deviation (CSAD) criterion.

Poyser (2018) investigated the April 29, 2013 - April 3, 2018 period for 100 cryptocurrencies, and Chang et al. (2000) investigated whether herd behavior is in existence by using CSAD criterion and Markow Switching approach. In the both of these studies they found that investors deviated from the financial asset pricing approach and followed the community when feeling pressure in the market. In contrast, Bouri et al. (2018) used the rollling window analysis to emphasize that the herd has changed over time in the market. Vidal-Tomás et al. (2018) analysed 65 digital currencies and they found that the smallest cryptocurrencies developed as the same way with the largest ones.

\section{DATA}

The study investigates whether there is a tendency towards herd behavior in the crypto asset market. Since the trend of herd behavior is also more likely to occur in high frequency data (Christie \& Huang, 1995), the analysis included the daily prices of 22 major, high trading volume cryptocurrencies (Bitcoin, Ethereum, Ripple, Tether, Bitcoin Cash, Litecoin, EOS, Binance Coin, Stellar, Tron, Cardano, Tezos, Neo, Cosmos, Dash, IOTA, UNUS SED LEO, NEM, Maker, Ethereum Classic, USD Coin, Huobi Taken), which combined represented an average of more than $85 \%$ of the market value from August 2013 to December 2019.. The criteria and constraints used for data and the definition of the highest trading volume are: (i) Market value, (ii) Market volume, (iii) Availability of data for estimation. In this framework, the empirical study investigated whether herd behaviour was present in crypto asset market, using the 22 cryptocurrencies with the highest trading volume with the specified criteria. The closing prices of cryptocurrencies are obtained from the internet address $\mathrm{https}$ ///coinmarketcap.com. Analyzes were made in the R program.

\section{METHODOLOGY}

To date, several methods have been developed to test the empirical herd in the prices environment. Herd behavior in financial markets was analyzed using different methodologies (Lakonishok et al., 1992; Wermers, 1995; Hwang \& Salmon, 2004; Christie \& Huang, 1995; Chang et al., 2000). In the literature section, it is stated that direct observation of investors' actions is the best approach to testing herds, due to the coordination mechanism and the potential to lean towards social convention. However, direct observation is almost impossible, due to the privacy in the cryptocurrency market. In this study, therefore, crypto asset prices were followed as a coordination mechanism for the trend of herd behavior. Given that the herd cannot be measured directly from financial markets, the literature has developed different proxies to detect herd behavior based on return regression tests. This study uses the methodology of Chang, Cheng and Khorana (2000), an improvement on Christie and Huang's (1995) original methodology. Christie and Huang (1995) argue that herd behavior occurs mainly during market fluctuation (Galariotis et al., 2016). Due to the increasing uncertainty in these periods, market participants tend to follow the collective behaviour of the market. When these behaviors are reflected in returns, deviations from market returns will decrease, due to the tendency to cluster around the market average. The criterion showing these deviations is the CSAD - Cross Sectional Absolute Deviation method (Doğukanlı \& Ergun, 2011). According to this method of detecting deviations, the herd trend is observed when there is no deviation 
from the mean or trend. This method was first used by Christie and Huang (1995). The Cross Sectional Standard Deviation (CSSD) criterion was proposed by Christie and Huang (1995), and Chang et al. (2000) developed Cross Sectional Absolute Deviation (CSAD) criteria, which is the method used in the current study.

Chang et al. (2000) 's Cross Sectional Absolute Deviation (CSAD) criterion is a method that takes into account structural breaks and nonlinearity. For this reason, in this study, it is investigated whether herd behavior is in question by using the preferred CSAD criterion and Markow Switching approach.

The CSAD method can be formulated as follows:

$$
C S A D_{t}=\frac{1}{N} \sum_{i=1}^{N}\left|R_{i, t-} R_{m, t}\right|
$$

$R_{i, t} \mathrm{i}$. i shows the return of the asset at the moment of $\mathrm{t}, R_{m, t}$ shows the market return

In the study, the CSAD model was estimated as follows:

$$
C S A D_{t}=\alpha_{S_{t}}+\beta_{S_{t}}\left|R_{m, t}\right|+\gamma_{S_{t}} R_{m, t}^{2}+\phi_{S_{t}} C S A D_{t-1}+\varepsilon_{t}
$$

where $\varepsilon_{t} \sim N\left(0, \sigma_{S_{t}}^{2}\right)$.

Following terminology and variables were used to test whether there is herd behavior in the cryptocurrency market in the model. CSAD: the horizontal cross-section absolute deviation coefficient, $\mathrm{R}^{2}{ }_{\mathrm{mt}}$ : crypto return and $\mathrm{R}_{\mathrm{mt}}$ : the absolute value of the difference of the weighted market return.

Transition probabilities $p_{i j}$ are defined as the probability switching from regime $j=1,2,3$ to regime $i=1,2,3$, giving the transition probability matrix

$$
P=\left[\begin{array}{lll}
p_{11} & p_{12} & p_{13} \\
p_{21} & p_{22} & p_{23} \\
p_{31} & p_{32} & p_{33}
\end{array}\right]
$$

The regime duration for regime $i=12,3$ is defined as $\tau_{i}=1 /\left(1-p_{i i}\right)$. Here $\mathrm{P}_{11}$ gives the possibility of being in the first regime in the next period, when the process is in the first regime; $\mathrm{P}_{22}$ gives the possibility of remaining in the second regime while the process is in the second regime. $\mathrm{P}_{12}$ gives the possibility of switching to the second regime in the next period while the process is in the first regime. In addition, the parameters must fully meet the probability rules, that is, they must be statistically significant (Aydın \& Kara, 2014: 36).

\section{HERD BEHAVIOR IN THE CRYPTO ASSET MARKET: EMPIRICAL RESULTS}

Descriptive statistics for the data used for the CSAD model are shown in Table 1. The average of the CSAD variable, consisting of 12409 observations, is 3.8005. The standard deviation of the variable is 2.8326 . The observations of this variable range from 0.0285 to 40.8122 . The skewness value shows that the observations of the CSAD variable are right-skewed, and the kurtosis value indicates that the observations of this variable are clustered closer to the average, that is, it shows a rather steep distribution. According to Jarque-Bera statistics, the error term shows a normal distribution. Ljung-Box statistics show that there is autocorrelation in the CSAD variable at the 1st and 5th delays, while the ARCH statistic shows that variance varies in both 1 delay and 5 delays. However, these effects are eliminated in 5 lag lengths.

Analysis of the yield curve of the crypto asset market shows a volatility cluster in 2014 . Volatility greatly increased during this period, but tended to return to the average in the post period. However, volatility increased after 2017 and returned to the average in the post-2019 period, providing some evidence for the presence of herd trend. 
Table 1: Descriptive Statistics

\begin{tabular}{llcc}
\hline & CSAD & $\left|R_{m}\right|$ & $R_{m}^{2}$ \\
\hline$N$ & 12409 & 12409 & 12409 \\
Mean & 3.8005 & 3.1068 & 23.6550 \\
S.D. & 2.8326 & 3.7428 & 93.5987 \\
Min & 0.0285 & 0.0010 & 0.0000 \\
Max & 40.8122 & 53.2046 & 2830.7323 \\
Skewness & 4.0056 & 3.7852 & 16.9515 \\
Kurtosis & 29.9258 & 27.2999 & 415.0673 \\
JB & $96105.9970^{* * *}$ & $80370.9440^{* * *}$ & $17364898.4040^{* * *}$ \\
Q(1) & $470.6125^{* * *}$ & $237.0609^{* * *}$ & $145.5849^{* * *}$ \\
Q(5) & $1161.4403^{* * *}$ & $683.0719^{* * *}$ & $287.7634^{* * *}$ \\
ARCH(1) & $77.1522^{* * *}$ & $100.9143^{* * *}$ & $3.0455^{*}$ \\
ARCH(5) & $99.8536^{* * *}$ & $154.3119^{* * *}$ & $13.7481^{* *}$
\end{tabular}

The table shows descriptive statistics for the cross-sectional absolute deviation (CSAD), absolute market returns $\left(\left|R_{m}\right|\right)$ and squares of the market returns $\left(R_{m}^{2}\right)$. In addition to number of observations (n), standard deviation (S.D.), the mean, maximum (Max), minimum (Min), kurtosis, and skewness, the table also displays the first [Q(1)] and fourth-order $[\mathrm{Q}(5)]$ Ljung-Box test for autocorrelation, Jarque-Bera normality test (JB),fourth-order $[\mathrm{ARCH}(5)]$ and the first $[\mathrm{ARCH}(1)]$ test for autoregressive conditional heteroskedasticity. Superscripts ***, **, and $*$ denote significance at $1 \%, 5 \%$, and $10 \%$ level, respectively. See the note to Figure 1 variable definitions.

Due to the differences in the dynamic structure of the variables examined, and the datadependent structure of the CSAD model, there may be differences in the number of regimes and regime definitions for each series (Aydin \& Kara, 2014: 39). In the models, it is estimated that, under the assumption of the same the variance, the number of regimes is 3 for each series, in line with Christie and Huang (1995).

According to Christie and Huang (1995), in order to verify herd behavior, the coefficients of the predicted regressions should be statistically significant and negative. Negative and meaningful coefficients mean that investors behave similarly during stressful market periods. In the Model; Regime 3 is the period with the highest volatility, Regime 2 is the most positive period with volatility, and Regime 1 is the period with the best value and volatility.

Figure 1: Market return ( $\mathrm{x}$ axis : Years, $\mathrm{y}$-axis: Rate of return)

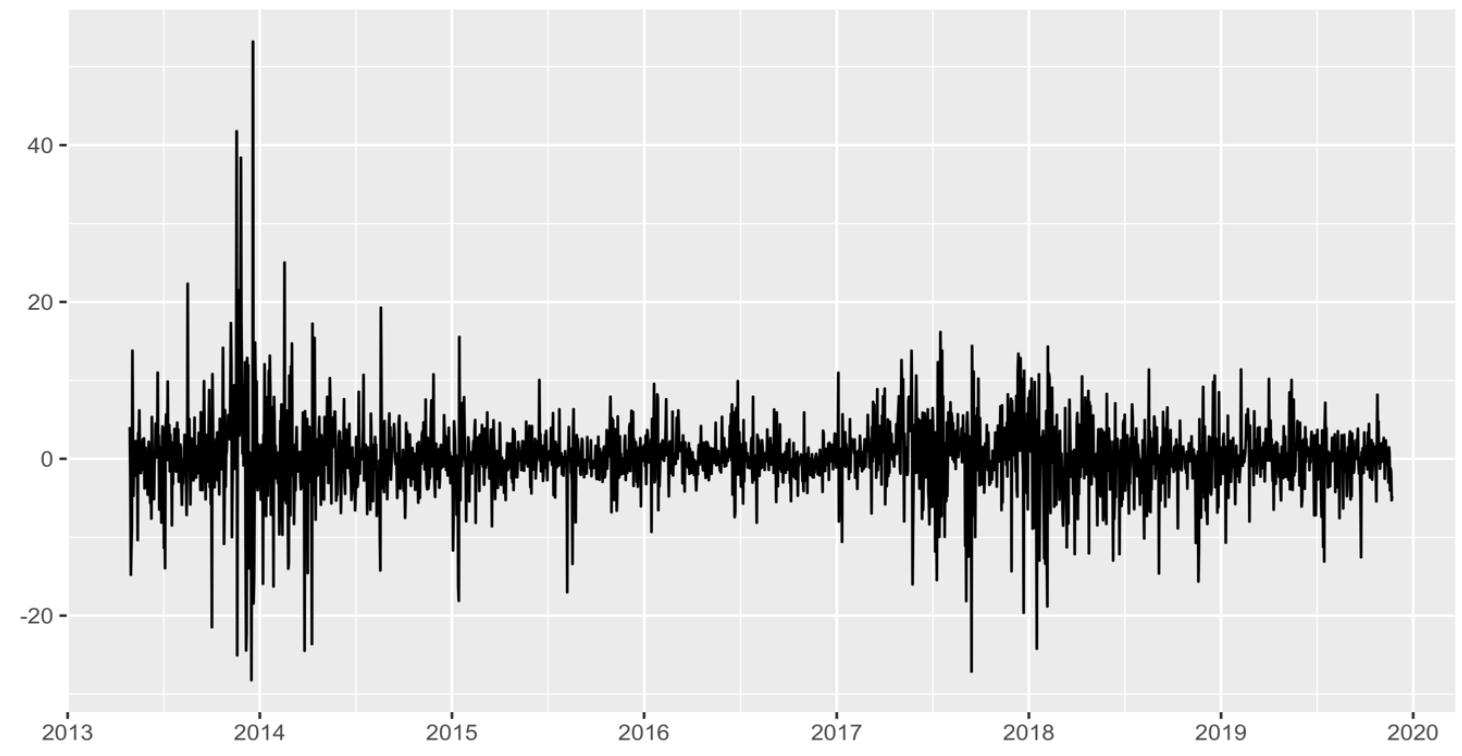


Table 2: Parameter Estimates

\begin{tabular}{llll}
\hline Parameter & Estimate & S.E. & t-statistics \\
\hline Regime 1 & & & \\
\hline$\alpha_{S_{t}}$ & $1.742^{*}$ & 0.091 & 19.163 \\
$\beta_{S_{t}}$ & $0.214^{*}$ & 0.023 & 9.520 \\
$\gamma_{S_{t}}$ & -0.000 & 0.002 & -0.200 \\
$\phi_{S_{t}}$ & $0.182^{*}$ & 0.031 & 5.858 \\
$\sigma_{S_{t}}$ & 0.726 & & \\
$R^{2}$ & 0.437 & & \\
Regime duration & 15.414 days & &
\end{tabular}

\section{Regime 2}

\begin{tabular}{llll}
\hline$\alpha_{S_{t}}$ & $5.080^{*}$ & 0.841 & 6.041 \\
$\beta_{S_{t}}$ & $0.805^{*}$ & 0.126 & 6.372 \\
$\gamma_{S_{t}}$ & $\mathbf{- 0 . 0 0 6}^{+}$ & 0.003 & -2.000 \\
$\phi_{S_{t}}$ & -0.033 & 0.067 & -0.490 \\
$\sigma_{S_{t}}$ & 4.546 & & \\
$R^{2}$ & 0.451 & & \\
Regime duration & 2.905 days & &
\end{tabular}

\section{Regime 3}

$\begin{array}{llll}\alpha_{S_{t}} & 1.726^{*} & 0.142 & 12.135 \\ \beta_{S_{t}} & 0.335^{*} & 0.037 & 8.997 \\ \gamma_{S_{t}} & \mathbf{- 0 . 0 1 2}^{*} & 0.002 & -5.950 \\ \phi_{S_{t}} & 0.326^{*} & 0.030 & 10.727 \\ \sigma_{S_{t}} & 1.688 & & \\ R^{2} & 0.287 & & \\ \text { Regime duration } & 8.915 \text { days } & & \end{array}$

Transition probabilities

\begin{tabular}{llll} 
& Regime 1 & Regime 2 & Regime 3 \\
Regime 1 & 0.935 & 0.000 & 0.055 \\
Regime 2 & 0.000 & 0.655 & 0.058 \\
Regime 3 & 0.065 & 0.345 & 0.888 \\
& & & \\
& AIC & BIC & logLik \\
& 8790.028 & 8952.805 & -4383.014 \\
\hline
\end{tabular}

Note: ${ }^{*}$ and ${ }^{+}$denotes significance at $1 \%$ and $5 \%$, respectively.

According to the results predicted in Table 2, the probability of the regime remaining in the period with the highest volatility (Regime 3 ) was $88.8 \%$, while in the period when the volatility was low (Regime 2), the probability of the market remaining in the period with low volatility again was $65.5 \%$. The probability of monitoring a period in which the market returns are highest with a high return (Regime 1) is 93.5\%. These results suggest that regime 1 and regime 3 are more stable than regime 2 for the crypto asset market, and that the herd members follows each other. It is seen that the probability of the market going to the 3rd regime when it is in the 2 nd regime is $5.8 \%$ and likewise the possibility of going to the 2nd regime when it is in the 3rd regime is $34.5 \%$. This result shows that a volatile market was unable to immediately reduce its volatility e volatile due to the herd effect. On the other hand, as can be seen from Table 2, only Regime 1 and 3 are statistically significant, revealing that herd tendency is not observed in 
Regime 2. Statistically significant coefficientsin regimes 1 and 3 indicate a tendency to herd behavior.

Figure 2: Regime specific and conditional residuals of the MSH (3) model

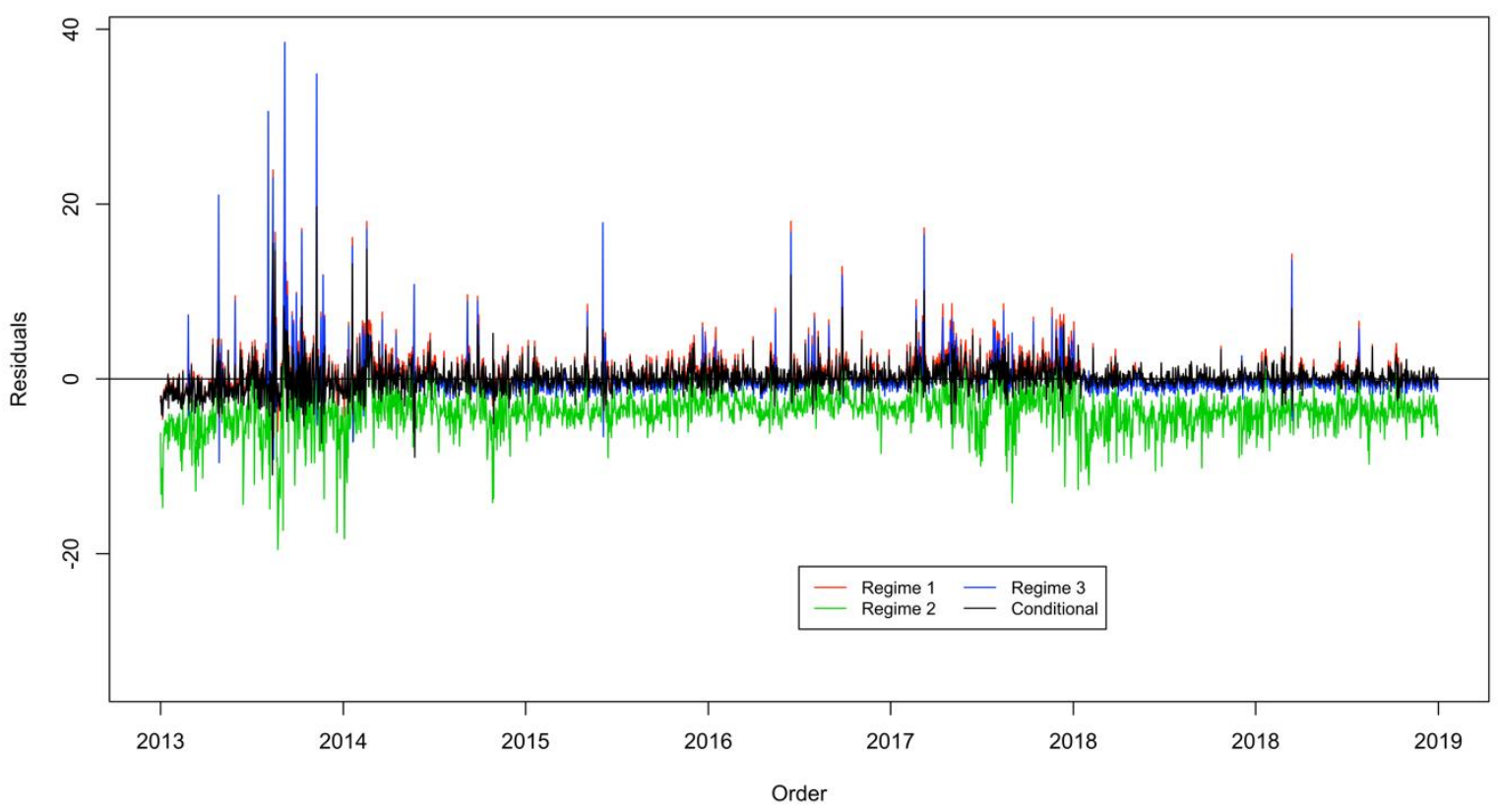

Figure 3: Smoothed regime 1 probabilities of the MSH (3) model
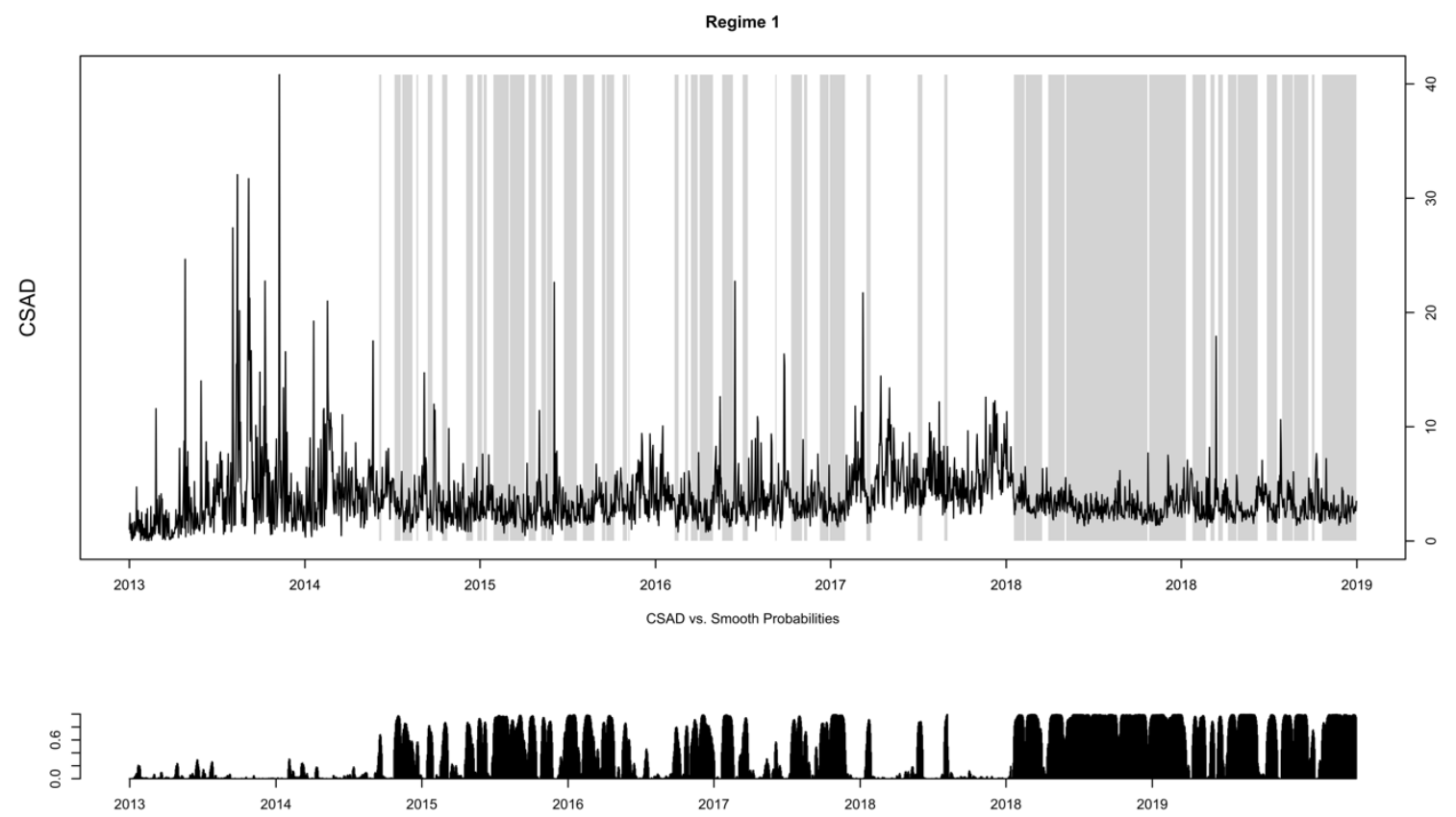

When the results are evaluated for the market; regarding regimes 1 and 3, which stated that the returns reached the highest, and are the most volatile, respectively, it is observed that they tend to remain, due to herd effects. The expected time estimated with $\tau_{i}=1 /\left(1-p_{i i}\right)$ for each regimen was determined as approximately 15414 days for regime 1, 2905 days for regimen 2 and 8915 days for regime 3 . From this point of view, it can be said that the regime with highest volatility and most intense herd psychology dominates the crypto asset market.

Figure 3 shows the frequency distribution of herd tendency behavior in regime 1 . While the herd trend in late 2013 accelerated the price of the crypto asset, it is observed that the herd trend 
has a higher frequency in January and August, and at the beginning of the month. Regime 1; It is the model with the highest volatility in both average and trend statistically.

Figure 4: Smoothed regime 2 probabilities of the MSH (3) model

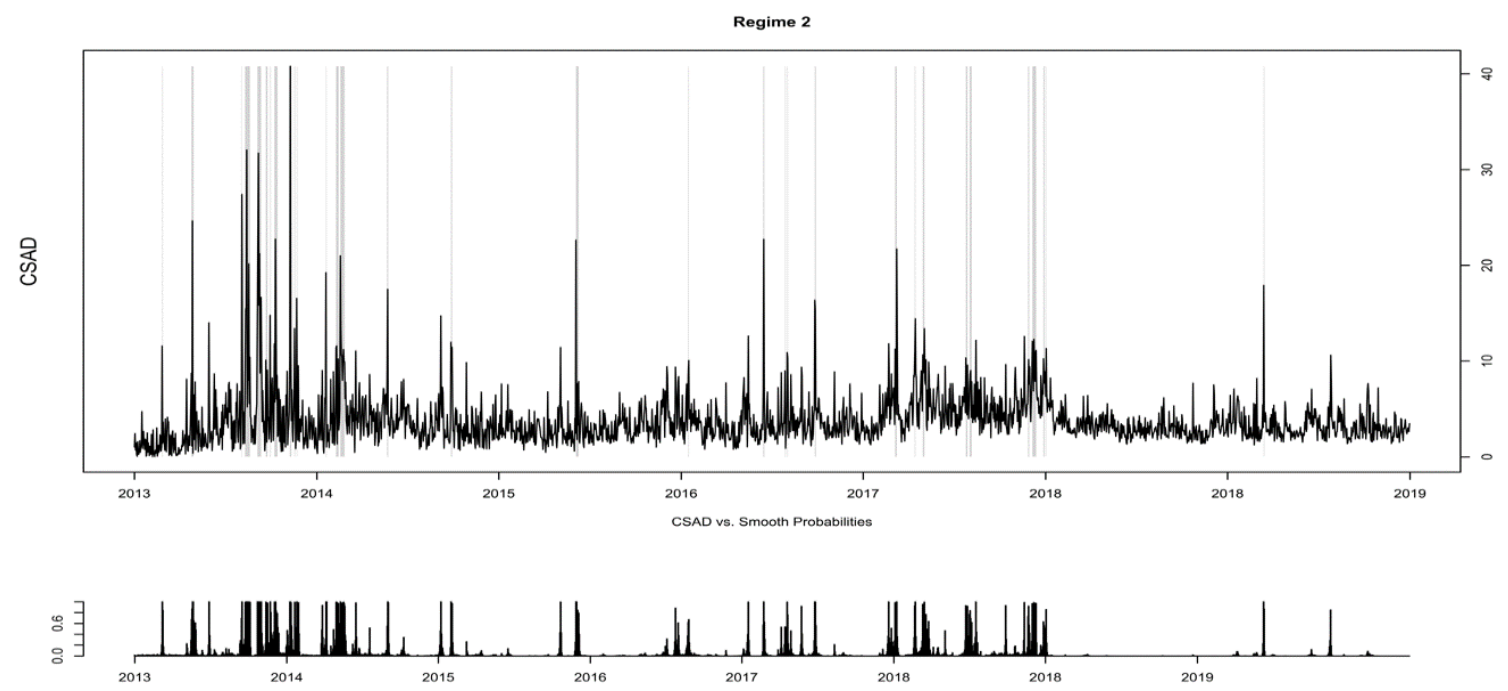

Figure 4 shows the frequency distribution of herd tendency behavior in regime 2. Although the coefficients are in positive relationship,, no herd tendency is observed.

Figure 5: Smoothed regime 3 probabilities of the MSH (3) model
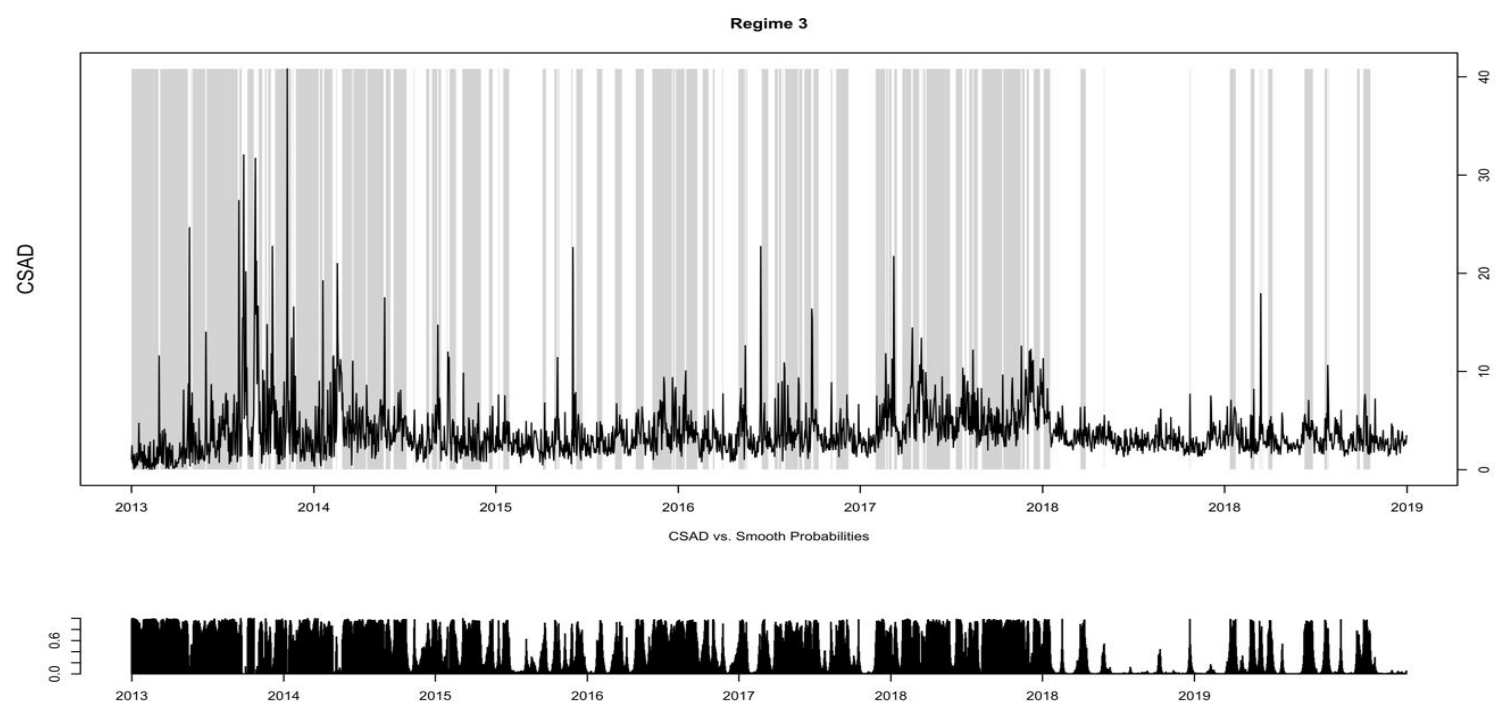

Figure 5 shows the frequency distribution of herd tendency behavior in regime 3 . In this regime model, the average and trend volatility is highest and the coefficients are significant. Although this is the worst regime in terms of volatility, herd tendency is observed in certain period intervals.

\section{CONCLUSION AND EVALUATION}

Herd behavior is defined in social psychology as individuals' following the the decisions of their group, overruling their own preferences. Herd behavior is considered the most influential behavioral trend in the process of individuals' investment decision making. 
Some studies in the literature support the herd behavior in the crypto markets, while others have reached the opposite conclusion. . According to Gama Silva et al (2019), cryptocurrency investors are more affected by negative than by positive information, showing risk aversion in the loss domain. In the current study, the Cross Sectional Absolute Deviation method was applied to investigate the herd trend reflected on the market among all active cryptos. Findings show that investors' tendency to show herd behavior is positive in Regime 1 and Regime 3 models. The analysis of daily frequency data reveal that the coefficients are statistically significant in these regimes.

Movements in the global financial markets cannot be considered independent from each other, and actions in the direction of trading between professional and non-professional investors will also interact at certain times. Any positive / negative shock reflected on the market will affect the value of the crypto asset. As the value of these assets increases, their growing use an investment tool will increasetheir value even further. . Therefore, herd behavior will continue to affect the market. In this study, herd behavior was measured with secondary data, and analysis results demonstrated its existence. However, the results in this study can be extended by investigating potential herd behavior in field studies, to shed further light on the causes of this behavior.

\section{REFERENCES}

Ağan, B., Aydın, Ü. (2019). "Global Movements of Crypto-Currencies: A Causality Analysis”, Journal of Applied Economics and Business Research, 9 (4), 1-12.

Aydın, Ü. and Ağan, B. (2016). "Rasyonel Olmayan Kararların Finansal Yatırım Tercihleri Üzerindeki Etkisi: Davranışsal Finans Çerçevesinde Bir Uygulama", The International Journal of Economic and Social Research, 12 (2), 95-112.

Aydın, Ü., Kara, O. (2014), “Kriz Öncü Göstergeleri ve Markov Rejim Değişimi Tekniğiyle Ekonominin Konjonktürel Yapısının Analizi”, Finans Politik \& Ekonomik Yorumlar Dergisi, 51 (592), 29-44.

Banerjee, A. V. (1992). A Simple Model of Herd Behavior. The Quarterly Journal of Economics, 107 (3), 797-817.

Bevan-Dye AL (2018). Relationship Between Generation Y Students' Link Sharing Motives and Word-Of-Mouth Communication On Facebook. International Journal of eBusiness and eGovernment Studies, $10 \quad$ (1), 1-17. $\quad$ Retrieved from https://dergipark.org.tr/tr/pub/ijebeg/issue/36107/405408

Bikhchandani, S., Hirshleifer, D., Welch, I. (1992). A Theory of Fads, Fashion, Custom, and Cultural Change as Informational Cascades. The Journal of Political Economy, 100 (5), 9921026.

Bouri, E., Gupta, R., Roubaud, D. (2019). Herding behaviour in cryptocurrencies. Finance Research Letters, 29, 216-221. Doi: 10.1016/j.frl.2018.07.008.

Chang, E. C., Cheng, J. W. and Khorana, A. (2000), An examination of herd behavior in equity markets: An international perspective, Journal of Banking \& Finance, 24 (10), 1651-1679.

Chang, S. G., Yu, B. S., and Fellow, M. V. (2000). Adaptive Wavelet Thresholding for Image Denoising and Compression, IEEE Transactions on Image Processing, 9 (9), 1532-1546. 
Cheah, E.-T., Fry, J. (2015). Speculative bubbles in bitcoin markets? An empirical investigation into the fundamental value of bitcoin. Economy Letters. 130, 32-36.

Chiang, T. and Zheng, D. (2010), An empirical analysis of herd behavior in global stock markets", Journal of Banking \& Finance, 34 (8), 1911-1921.

Christie, W.G. and Huang, R. D. (1995). Following the Pied Piper: Do Individual Returns Herd around the Market?", Financial Analysts Journal. July-August, 31-37.

Corbet, S., Lucey, B., Yarovaya, L. (2018). Datestamping the Bitcoin and Ethereum Bubbles, Finance Research Letters, 26, 81-88.

Demirer, R., Gubo, D. ve Kutan, A. M. (2007). An Analysis of Cross-Country Herd Behavior in Stock Markets: A Regional Perspective. Journal of International Financial Markets, Institutions and Money. 3. 123-142.

Demirer, R., Kutan, A. M., Chen, C. D. (2010). "Do Investors Herd in emerging Stock Markets?: Evidence from the Taiwanese Market", Journal of Economic Behavior \& Organization. 76: 283-295.

Devenow, A. and Welch, I. (1996). Rational Herding in Financial Economics, European Economic Review, 40, 603-615.

Doğukanlı, H., Ergun, B. (2011). IMKB'de Suru Davranışı: Yatay Kesit Temelinde Bir Araştırma. 10. Ulusal İşletmecilik Kongresi Kitapcığı. 355-358.

Fama, E. F. (1970). "Efficient Capital Markets: A Review of Theory and Emprical Works", Journal of Finance, 25, 383-417.

Gama Silva, P.V.C., Klotzle, M.C., Pinto, A. C. F., Gomes, L. L. (2019) Herding behavior and contagion in the cryptocurrency market. Journal of Behavioral and Experimental Finance, 22, 41-50.

Gleason, K. C., Mathur, I., Peterson, M. A. (2004). Analysis of intraday herding behavior among the sector ETFs, Journal of Empirical Finance. 11, 681-694.

Hirshleifer, D. A. and Teoh, S. H. (2002) Limited Attention, Information Disclosure, and Financial Reporting. JAE Boston Conference Available at SSRN: https://ssrn.com/abstract=334940 or http://dx.doi.org/10.2139/ssrn.334940.

Hwang, S. and Salmon, M. (2004). "Market Stress and Herding”, Journal of Empirical Finance, $11,585-616$.

Ji, Q., Bouric, E., Guptad, R., Roubaud, D. (2018). Network causality structures among Bitcoin and other financial assets: A directed acyclic graph approach, The Quarterly Review of Economics and Finance, 70, 203-213.

Katsiampa, P. (2017) Volatility Estimation for Bitcoin: A Comparison of GARCH Models" Economics Letters, 158 (C) 3-6.

Lakonishok, J., Shleifer, A. ve Vishny, R., W. (1992). The Impact of Institutional Trading on Stock Prices. Journal of Financial Economics. 32, 23-43. 
Platanakis, E., Sutcliffe, C., Urquhart, A. (2018). "Optimal vs naïve diversification in cryptocurrencies," Economics Letters,171(C), 93-96.

Poyser, Obryan; (2018), "Herding behavior in Cryptocurrency Markets," Papers 1806.11348, arXiv.org, revised Nov 2018.

Şanlısoy, S, Çiloğlu, T. (2019). An Investigation On the Crypto Currencies and Its Future. International Journal of eBusiness and eGovernment Studies, 11 (1), 69-88. Doi: 10.34111/ijebeg.20191115

Urquhart, Andrew, (2017). Price Clustering in Bitcoin, 1-7, https://papers.ssrn.com/sol3/papers.cfm?abstract_id=3001719,

Vidal-Tomás, D., Ibañez, A. (2018), Semi-strong efficiency of Bitcoin. Finance Research Letters, 27, 259-265.

Wei, W. C. (2018). The Impact of Tether Grants on Bitcoin, https://papers.ssrn.com/sol3/papers.cfm?abstract_id=3175876.

Wermers, Russ; (1995), Herding, Trade Reversals, and Cascading by Institutional Investors, unpublished; University of Colorado, Boulder. 